\title{
Scaling fish metacommunities in stream networks: synthesis and future research avenues
}

\section{T. Erős}

\author{
Balaton Limnological Institute, MTA Centre for Ecological Research, Klebelsberg K. u. 3., H-8237 Tihany, Hungary. \\ Tel.: +3687448244,Fax: +3687448006,E-mail: eros.tibor@okologia.mta.hu
}

Key words: Community variability, Dispersal, Diversity, Environmental filtering, Metacommunity, Rivers.

\begin{abstract}
The metacommunity perspective has substantially advanced our understanding of how local (within community) and dispersal (between community) processes influence the assembly of communities. The increased recognition of dispersal processes makes it necessary to re-evaluate former views on community organization in different ecological systems and for specific organisms. Stream systems have long been considered from a linear perspective, in which local community organization was examined along the longitudinal profile, from source to mouth. However, the hierarchically branching (i.e. dendritic) structure of stream networks also significantly affects both local and regional scale community organization, which has just only recently been fully recognized by ecologists. In this review, I examine how the shift from a strictly linear to a dendritic network perspective influenced the thinking about the organization of fish metacommunities in stream networks. I argue that while longitudinal patterns in the structure of fish communities are relatively well known, knowledge is still limited about how the structure of the stream network ultimately affects the spatial and temporal dynamics of metacommunities. I suggest that scaling metapopulation models up to the metacommunity level can be useful to further our understanding of the spatial structure of metacommunities. However, this requires the delineation of local communities and the quantification of the contribution of dispersal to local community dynamics. Exploring patterns in diversity, spatial distribution and temporal dynamics of metacommunities is not easily feasible in continuous stream habitats, where some parts of the habitat network are exceptionally hard to sample representatively. Combination of detailed field studies with modelling of dispersal is necessary for a better understanding of metacommunity dynamics in stream networks. Since most metacommunity level processes are likely to happen at the stream network level, further research on the effects of stream network structure is needed. Overall, separation of the effect of dispersal processes from local scale community dynamics may yield a more mechanistic understanding of the assembly of fish communities in stream networks, which may also enhance the effectiveness of restoration efforts.
\end{abstract}

Abbreviations: NDH-Network Dynamics Hypothesis, RCC-River Continuum Concept.

\section{Introduction}

The increased recognition of the role of spatial processes in the organization of ecological communities was one of the greatest breakthroughs in community ecology in recent decades (Dray et al. 2012). Although former models of community organization emphasized the importance of within patch environmental characteristics and biotic interactions, more recent studies attempt to disentangle the role of dispersal in the network of habitat patches, and consequently, the role of local and regional scales in the assembly of species into local communities (Vellend 2010). This approach is the main research avenue of the metacommunity concept, which considers the structure and dynamics of multiple local communities linked by dispersal (Leibold et al. 2004).

There are four "paradigms" of metacommunity theory: species sorting, mass effects, neutral and patch dynamics. These paradigms have different, but nonexclusive assumptions about the role species identity, quality of the habitat and local (niche differences through interspecific competition or sorting mechanisms along ecological gradients) and regional factors (dispersal, demographic stochasticity among sites) play in the organization of the metacommunity (Leibold et al. 2004, Chase and Bengtsson 2009). However, since metacommunity paradigms are not mutually exclusive, and communities may in fact be organized by a combination of processes (including neutral ones), recent studies highlight the continuity among these paradigms (Gravel et al. 2006). They emphasize a shift in focus "from separating the four originally postulated paradigms to more concisely testing the mechanisms and relative importance of spatial (i.e. dispersal related) and local (i.e. niche related) processes" (Logue et al. 2011, Winegardner et al. 2012).

The differences from a local to regional perspective between past and current community ecological research makes it necessary to re-evaluate former views on community organization in different ecological systems and for specific organisms. Stream networks exhibit a unique spatial structure in the landscape. The linear, hierarchically branching (i.e. dendritic) habitat structure may significantly affect both local and regional (i.e. landscape scale) community organization, which has been fully recognized by ecologists only recently (Campbell-Grant et al. 2007, Brown et al. 2011,Erős et al. 2012a, Altermatt 2013). Fishes are ideal model organ- 
isms for the examination of metacommunity organization in stream networks. Unlike many macroinvertebrates or algae, stream dwelling fishes are incapable of overland dispersal, and therefore their movement is restricted strictly to within a given stream. In addition, fishes exhibit very different movement patterns (Lucas et al. 2001). Therefore, fishes qualify as an excellent group to study the role of dispersal across a variety of scales in stream networks. Despite this, our knowledge is still limited on the relative role of local and regional scales in their diversity and community organization (Falke and Fausch 2010, Peres-Neto and Cumming 2010, Erős et al. 2012b).

One of the most influential concepts of community organization in stream fish ecology was that of Schlosser's model $(1982,1985,1987,1990)$ on warm-water streams in the midwestern United States. Schlosser $(1987,1990)$ proposed that small streams represented an ecological gradient along which upstream fish assemblages were relatively variable with low species richness and downstream assemblages relatively stable, with high species richness. The causal factors producing this pattern involve stability of the physical environment and habitat complexity, with upstream reaches being physically variable and structurally simple, whereas downstream reaches have the opposite characteristics. This linear perspective of stream systems was inspired by the view of the most important concept of that era, the River Continuum Concept (hereafter RCC, Vannote et al. 1980), which predicted patterns and processes in river systems from source to mouth, along the longitudinal profile of rivers. This view generated a flurry of research on the organization of fish communities in linear stream systems, especially in small and medium sized streams (Zalewsky et al. 1990, Roberts and Hitt 2010). It has been recognized, however that changes in abiotic and biotic conditions along the longitudinal profile cannot really explain differences in fish diversity among many streams of similar size. For example, streams which flow into substantially larger streams (i.e. adventitious streams) have been shown to be more species rich and in many cases have more variable communities than streams which flow into similar sized streams (Gorman 1986, Osborne and Wiley 1992, Schaeffer and Kerfoot 2004). A more regional (i.e. landscape ecological) perspective was needed to better understand patterns in diversity and community organization in stream networks (Schlosser 1991, Matthews and Robison 1998, Fausch et al. 2002, Clarke et al. 2008).

The purpose of this review is to synthesize how the shift from the strictly linear to a dendritic network perspective influenced the thinking of stream ecologists in general, and stream fish ecologists in particular in understanding metacommunity organization. Although significant progress has been made in the last two decades in the field of stream fish ecology (Matthews 2010, Fausch 2010), these studies have not been synthesized in the context of metacommunities (Falke and Fausch 2010), and especially not from a network perspective. I believe that a synthesis of the current literature and suggestions for future research directions (see Table 1) may help to advance further research and provide new per- spectives in understanding fish metacommunity organization in dendritic stream networks.

In this review, I first briefly examine the structure of stream networks as the habitat template for fishes. Then, I examine fish communities from the viewpoint of metacommunity organization. I propose the extension of metapopulation models to the metacommunity level, which approach may help to better understand the organization of metacommunities in a spatially more explicit manner. Then, I overview our current knowledge on diversity and the role of environmental heterogeneity and dispersal in spatio-temporal metacomunity organization. Finally, I briefly discuss conservation aspects. Throughout the paper, I pay special attention to the importance of scaling in examining patterns in metacommunities and in the determining processes.

\section{The habitat template: scaling the structure of stream networks}

The role of hydrological and geomorphological processes has long been recognized in the organization of stream fish communities. For example, clearly recognizable changes in slope, size, velocity and substrate composition along the longitudinal profile have led to the subdivision of the river course (Illies and Botosaneanu1963, Aarts and Nienhuis 2003, Lasne et al. 2007). Most systems distinguish the steep and torrential upper course (or rhithron) and the flat, slow-flowing lower course (or potamon) (Welcomme 1985), which can be further divided to subsections (Fig. 1). These hydrogeomorphically different sections ("patches") have more or less distinct fish communities, and in many systems have been named by their characteristic fish species (Matthews 1986, Aarts and Nienhuis 2003, Lasne et al. 2007).

It is less recognized that the spatial extent of hydrogeomorphically different sections can differ substantially. For example, the length of the rhithron is much shorter than the length of the potamon if only the single longitudinal profile of the river is considered from source to mouth (Fig. 1). The difference is so substantial that the potamon can be one or two orders of magnitude longer than the rhithron. On the contrary, due to the dendritic (or branching) structure of stream networks, the number of potamal sections is much lower than the number of rhitron sections. Therefore, at the stream network level, the total length of the rhithron can be longer than the overall length of the potamon, depending on the structure of the studied stream network. Such differences in number and length of the environmentally different sections may substantially affect the landscape level diversity and structure of stream communities (Clarke et al. 2008, Finn et al. 2011). Therefore, it is important to consider the network level effect of geomorphology on communities, where the structure of the riverine network is not reduced to a single unbranched linear system (Fisher 1997, Ganio et al. 2005, Campbell-Grant et al. 2007).

Recently, several studies have shown how the shape and configuration of dendritic networks influence within-network physical processes, and consequently, the habitat template 
Table 1. Summary of key scientific challenges and timely questions addressed in this paper to advance understanding the metacommunity organization and conservation of fishes in stream networks.

Challenge 1: The delineation of communities and metacommunities in stream networks

- To what extent hydrogeomorphic patches determine the separation of communities in different parts of the stream network?

- To what extent local communities can be delineated in the landscape which may form a metacommunity?

- What are the dispersal differences between individual species, and how does this influence the delineation of metacommunities?

- Which are the best methodological approaches (e.g. species vs. community level approaches, classification and ordination analyses) to study the formation of metacommunities in different parts of the stream network?

- Which metacommunity models are the most suitable for stream metacommunities and how do these depend on network structure and position?

Challenge 2: Understanding the spatio-temporal organization of fish metacommunities

- How sample representativeness influence inferences on within and between community diversity and how does this depend on network position?

- How does dendritic network structure determine within and between community diversity in the metacommunity network and what is the surplus information that this variable group can add over within stream and landscape level environmental variables in understanding metacommunity organization?

- What is the relative role of local and regional (dispersal) processes in metacommunity organization and how does this depend on spatial and temporal scales?

- To what extent neutral models can be used to understand metacommunity organization, and what is the surplus information what can be gained by niche based ecology?

- How does the stability of communities depend on dispersal in the metacommunity network, and how does stability depend on network structure and position?

Challenge 3: Conservation management of metacommunities

- How important is the maintenance of dispersal in conserving local communities compared with within stream environmental heterogeneity?

- Which metacommunities are the most valuable (e.g. based on naturalness, diversity, size, dispersal possibilities) in the landscape for conservation purposes?

- Which are the most valuable local communities within the metacommunity network for conservation purposes?

- How restoration strategies should be refined depending on metacommunity types (e.g. patchy, source-sink, nonequilibrium)?

- How will climate change and future degradation of the habitat (e.g. spread of invasive species, habitat deterioration, dam effects) will modify the spatial structure of metacommunities and which metacommunities (and local communities within metacommunities) are the most prone to such effects?

Figure 1. Approximate spatial extent of different hydrogeomorphic reaches in a temperate zone, great river along the longitudinal profile and the associated characteristic fish species. These reaches may serves as basic habitat units (i.e., functional process zones sensu Thorp 2014, Thorp et al. 2006) for delineating fish (meta)communities in stream networks. Note that the rhithron forms only a tiny portion of the longitudinal profile, however its importance can be significant in a network context. Note also that reaches in the rithron can be very close and very far from each other (indicated by dashed arrows), while reaches in the potamon, which are in more central position, are always relatively close to each other in the stream network (indicated by dotted arrows).

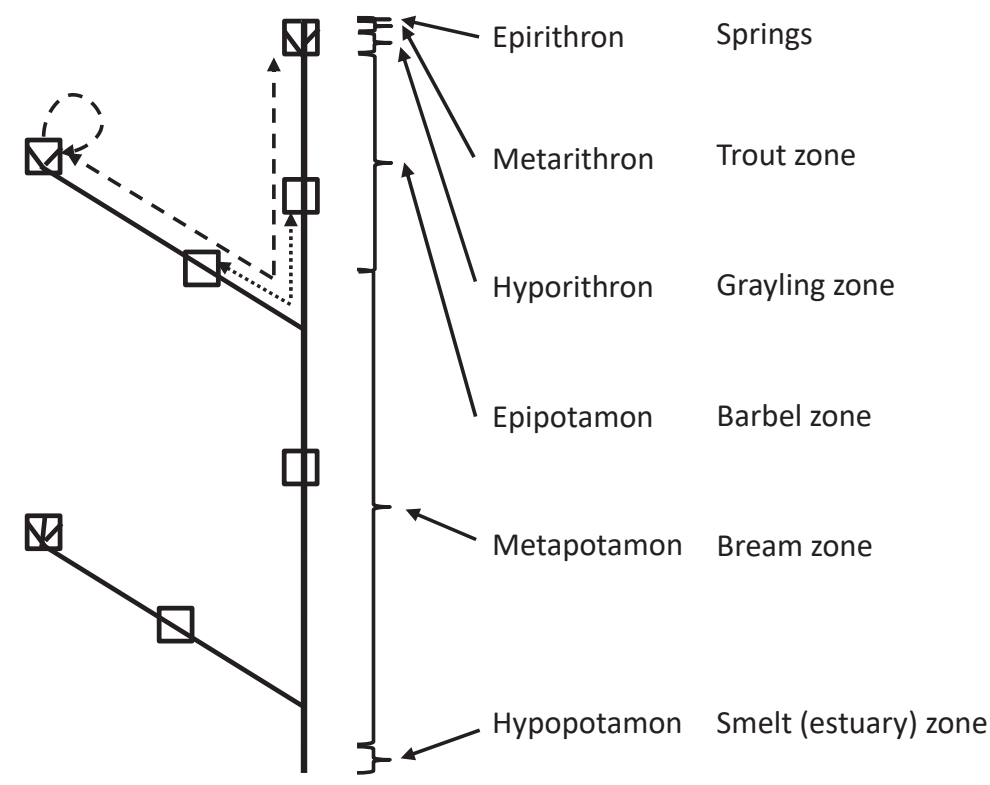


which shapes community organization (Poole 2006). Benda et al. (2004a) developed the network dynamics hypothesis $(\mathrm{NDH})$, which emphasizes the importance of network structure and especially the role of confluences on channel morphology. They showed, for example, how network configuration and the associated basin shape influence the importance of confluence effects on mainstem rivers (Benda et al. 2004a,b). They predicted that more compact heart shaped basins contain more geomorphically significant confluences (i.e., which significantly modify the hydrogeomorphology of the receiving rivers) than more elongated linear or rectangular basins. Strong support of the NDH was given by Rice (2017), who demonstrated that compact basins contained twice as many significant confluences as linear basins and that doubling basin area almost doubled the number of geomorphically significant confluences. These and other studies thus provided compelling evidence that basin morphometry affects sediment connectivity and riverscape heterogeneity in stream networks (Rice et al. 2008). Quantification of network structure has also improved significantly. For example, Erös et al (2011, 2012a) showed that network based indices can provide novel measures for the quantification of network structure, and the diversity of connectivity relationships in stream systems. They suggested that quantification of connectivity relationships is at least as important a variable for characterizing riverscape diversity at the landscape scale as instream habitat diversity, and should be more intensively considered in fundamental and applied research. Innovative geostatistical methods have been developed for the quantitative modelling of the structure and connectivity of stream networks, which can ease testing network level effects of the habitat template on community organization (Ganio et al. 2005, Peterson et al. 2013).

In sum, due to differences in climate (e.g., temperature, rainfall) and landscape characteristics (e.g., altitude, geology, erosion processes) subbasins with a variety of network structures can form in the basin of a great river (Fig. 2). Contrasting with the common view of rivers as continuous, longitudinal gradients in physical conditions, it can be fruitful to consider stream systems as networks, where nested, discontinuous hierarchies of hydrogeomorphic patches shape the organization of communities (Poole 2002, Thorp et al. 2006, Thorp 2014). The arrangement and spatial and temporal formation of these hydrogeomorphic patches (or 'functional process zones', sensu Thorp et al. 2006) may provide a useful template for the delineation of local fish communities. They may also substantially influence the role of environmental and dispersal processes in the organization of metacommunities.

\section{Back to basics: Defining fish metacommunities in stream networks}

For understanding the organization of metacommunities, their objective delineation is a prerequisite. By definition, a metacommunity is a community of communities, which is composed of a set of multiple local communities linked by the dispersal of community constituting species. However, local communities are composed of different species with contrasting spatial distribution and metapopulation dynam-

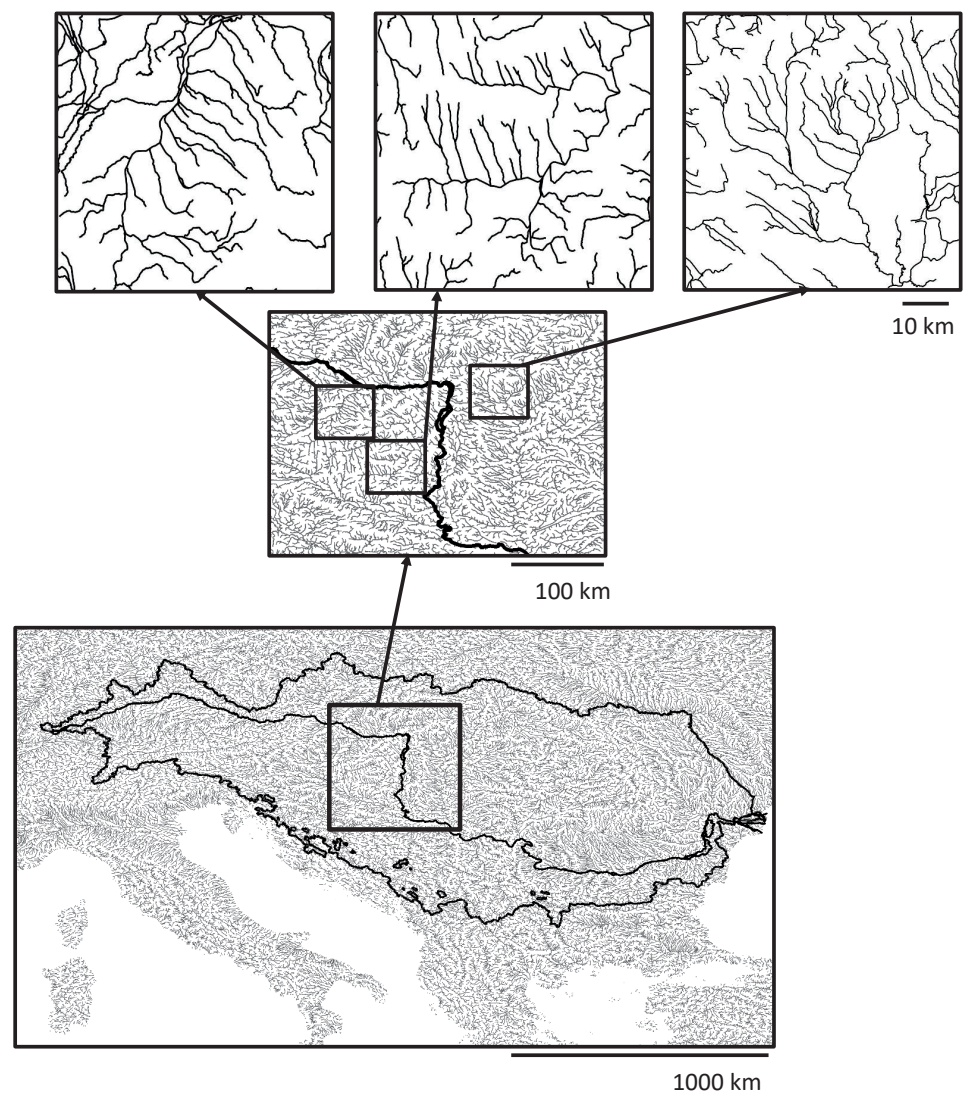

Figure 2. Due to differences in climate (e.g. temperature, rainfall) and landscape characteristics (e.g. altitude, geology, erosion processes) subbasins with a variety of network structures can form in the basin of a great river, for example, in the basin of the Danube River (Europe). Contrasting differences in the length and spatial configuration of the segments, as can be seen, for example, in the similar sized squares, may significantly influence metacommunity dynamics via their effects on dispersal processes. 
ics. Therefore, the delineation of metacommunities, where multiple species with different population boundaries co-exist even in a single metacommunity, is not always straightforward. In fact, many studies use the metacommunity concept without even considering what really constitutes a metacommunity in the studied system. Following this conceptual line, I propose that metacommunities should be defined using two important criteria: 1) how the constituting species perceive the heterogeneity of the environment, and consequently, how separable the local communities are from each other in the landscape based on their species composition and 2) the dispersal characteristics of the species. Several multivariate methods exist for grouping communities based on similarities in their community structure. For example, both classification and ordination methods are commonly used for grouping spatially separated communities (Legendre and Legendre 1998, Jackson 2010). The elements of metacommunity structure approach (see Leibold and Mikkelson 2002, Presley et al. 2010) can also help to define whether species show similar responses to environmental gradients, and therefore can be classified into well-defined, distinctive community types (i.e.,
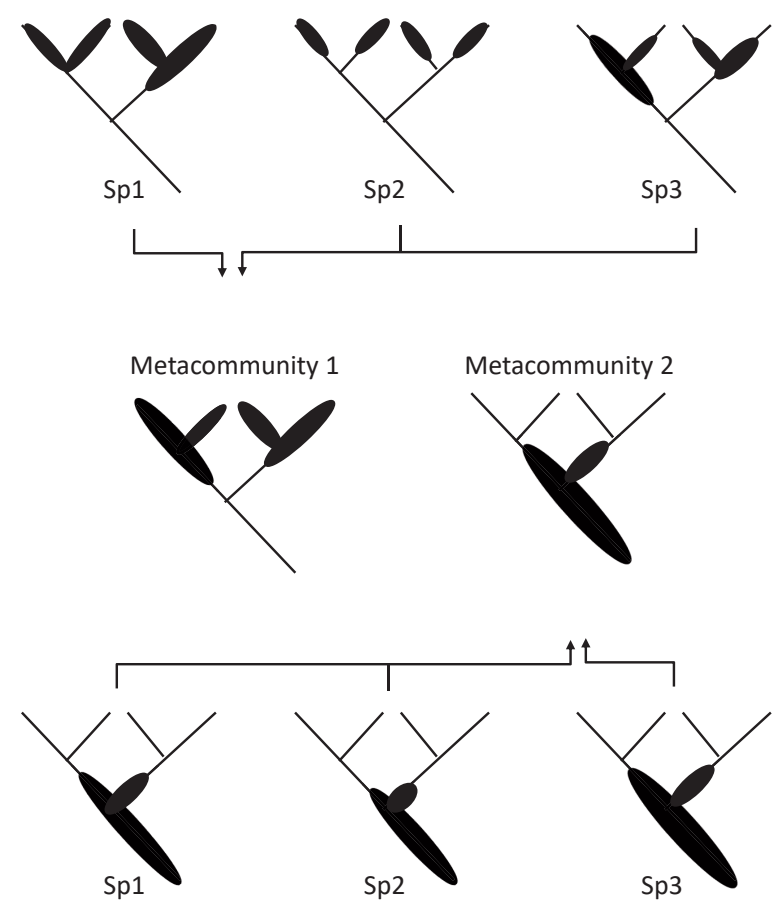

Figure 3. Defining metacommunities requires the separation of local communities, which are linked by dispersal in the network of communities. Separation of local communities, however depends largely on the patchiness of the habitat, the habitat affinity of community constituting species and their dispersal characteristics. Due to the dendritic structure of streams, headwater communities and those inhabiting the rhithron are more isolated and patchily distributed, while communities more downstream show more homogenous distribution. Since communities of downstream reaches are closer together they are less clearly separable from each other. Note, that in this example Sp1-Sp3 indicate the distribution of different hypothetical species in the stream network.
Clementsian distribution) or rather show individualistic responses that yield a continuum of gradually changing composition without clumping (i.e., Gleasonian distribution). These methods, coupled with knowledge about species dispersal, can help in the identification of metacommunities.

It should be noted that local communities may be more easily defined in patchy landscapes, where relatively clear boundaries in species distributions exist (Didham et al. 2012). However, separation of local communities may not always be simple in continuous habitats and/or in case of individualistic responses of species to environmental heterogeneity (Erös and Campbell-Grant 2015). For example, metacommunities of spatially more clearly separated headwater streams may be more easily delineated than communities of more downstream reaches, where hydromorphological conditions, and consequently differences in community structure are less clear (Fig. 3). Therefore, the responses of species to environmental heterogeneity and their dispersal characteristics largely influence how metacommunities can be perceived in stream networks and whether species or community level approaches are the most useful for understanding metacommunity dynamics. Nevertheless, the advantage of using a patchy landscape model (i.e., when the stream network is viewed as the set of different hydrogeomorphic patches) is that it may help to distinguish local communities, at least if species respond to the heterogeneity of the environment. Such an approach can provide a spatially explicit riverscape model for the examination of metacommunity organization (see below).

Naturally, community organization can be studied at a hierarchy of spatial scales. However, by definition, metacommunity ecology should address between-community interactions. It should therefore separate patterns and mechanisms which are related to between-community interactions from within-community dynamics (Fig. 4). In this regard, the primary scales of the study of fish metacommunities in stream systems are the network of reaches $\left(10^{-1}-10^{0} \mathrm{~km}\right)$ and segments $\left(10^{1}-10^{2} \mathrm{~km}\right)$, because their extent fits best to the movement patterns and population dynamics of most fish populations, and these are the units at which different fish communities form (Matthews 1986, 1998, Lasne et al. 2007, Erös et al. 2016). Spatio-temporal scaling is thus critical in separating within community patterns and processes from metacommunity dynamics.

For example, in a theoretical model of Great Plains (USA) stream fishes Falke and Fausch (2010) proposed that different "metacommunity dynamics" may be connected to the seasonal functional habitat use of the species in the community (Fig. 4.). They suggested that species may choose among different mesohabitats for spawning according to species sorting mechanisms in spring/early summer. Then they move to feeding and refuge habitats during summer/fall where mass effect mechanisms may govern species distribution between source and sink mesohabitat patches. Species then move to overwinter refuge habitats during winter where neutral or patch dynamics may shape community dynamics in relatively homogeneous mesohabitat patches. While this model is intuitively appealing, it characterizes within community patterns and processes, which should not be interpreted to be 


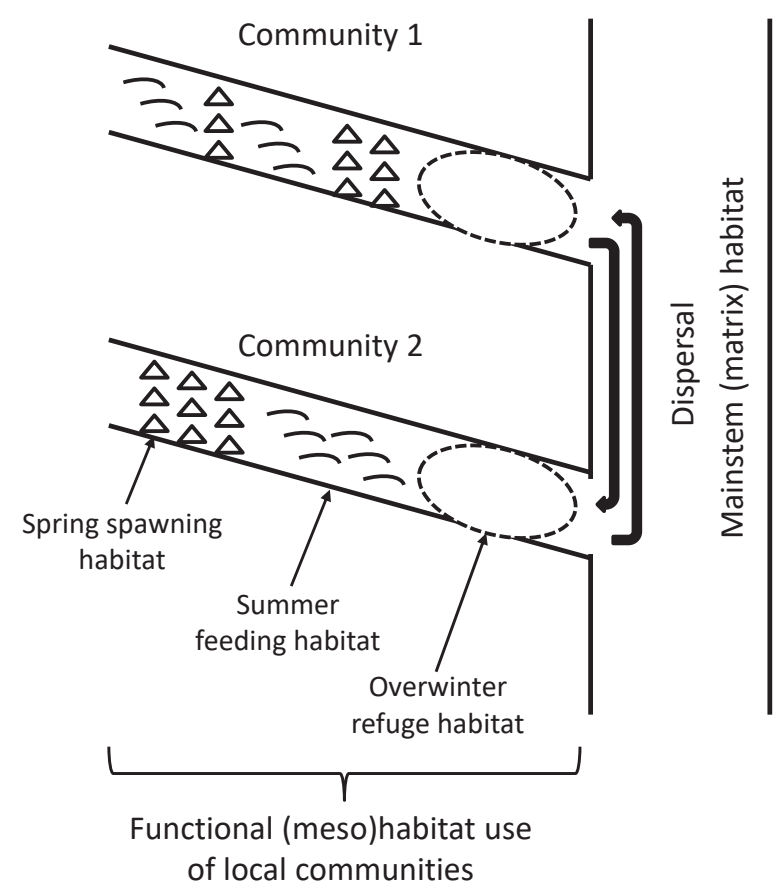

Figure 4. Functional habitat use of species in two local communities, which together form a metacommunity. Quantifying the degree of dispersal between the two communities is critically important to separate the role of regional (i.e. metacommunity level) processes from local community dynamics. Note, that in this example the mainstem river presents a matrix habitat for the majority of stream dwelling species, thus partially separating fish populations of the two streams.

metacommunity level mechanisms. Clearly, exploration of both within- and between-community (i.e., metacommunity) patterns and processes are important, and they may be difficult to delineate in highly dynamic stream systems, but they represent different spatial and temporal scales.

\section{Metacommunity types}

In metapopulation ecology, five classic models have been developed for defining the distribution of populations in space (Harrison 1991, Harrison and Taylor 1997), depending mainly on the importance of dispersal for the persistence of populations (Fig. 5). I suggest that metapopulation models can be extended to the metacommunity level for a more mechanistic understanding of the organization of metacommunities. I do not detail these models here (for details on stream fish see Schlosser and Angermeier 1995, Falke and Fausch 2010), but explain them in the context of their application to metacommunities.

(1) In a "classic"metacommunity, the local communities can be relatively well separated from other communities in the matrix of habitats, which have different communities (i.e., differences in species composition and abundance). In a classic metacommunity, most of the constituting species can be characterized by classic metapopulation dynamics. These species persist regionally only
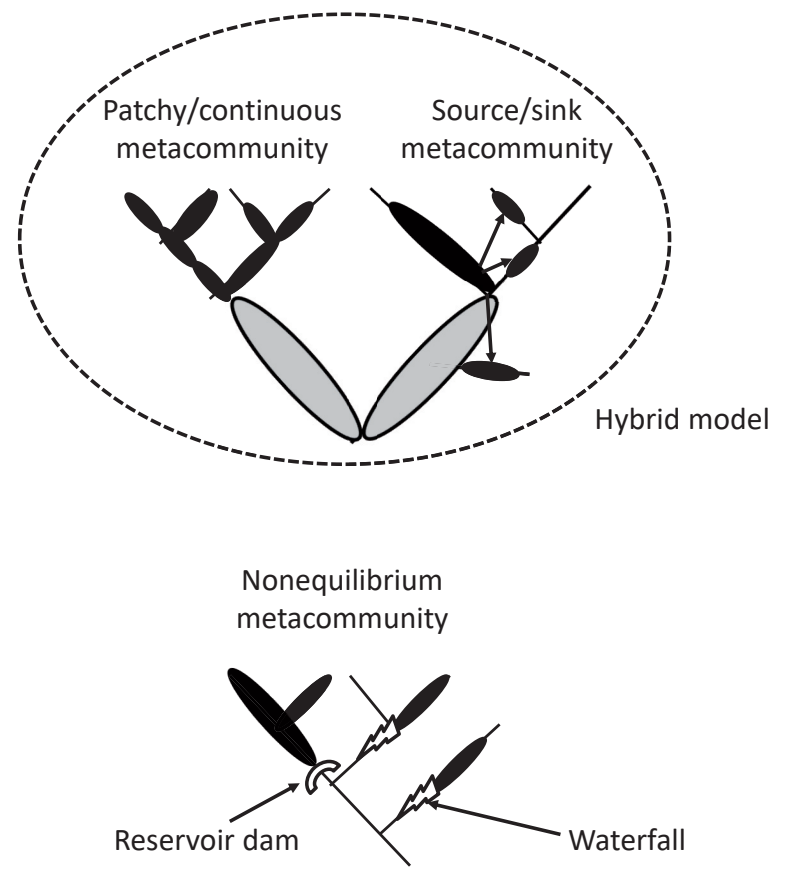

Figure 5. Theoretical examples of different types of metacommunities in stream networks. Grey patches show non-preferred (matrix) habitats (hydrogeomorphic units) where different communities exist. The hybrid model is the combination of other models, therefore its applicability may also depend on spatial scale. Nonequilibrium metacommunities may form in highly fragmented landscapes, which can be due to natural (e.g., waterfall, beaver dam) or anthropogenic (e.g. reservoir dam) effects. Note that the "classic" model is not shown since this model does not have reality in real landscapes.

in the presence of between-patch dispersal. However, the "classic" model assumes that the habitat patches are of equal size, patches are at the same distance from each other, and rates of colonization and extinction are equal. Therefore, this model may be unrealistic in nature both for metapopulations (Schlosser and Angermeier 1995, Falke and Fausch 2010) and for metacommunities.

(2) In a mainland/island or source/sink metacommunity, a core patch (or patches) may exist in the landscape with more stable (usually larger and more stable) populations than in neighbouring similar communities. Immigration from core patches (communities) is necessary for the maintenance of temporally unstable communities in sink patches.

(3) Patchy metacommunities are characterized by higher dispersal than in the classic model. In a patchy metacommunity, the dispersal rate is so high between similar patches/communities that the metacommunity may behave as a large local community. However, in a nonpatchy (or more continuous) environment population boundaries may not easily be defined, and the different local populations may form a continuum in the landscape (chain of populations). 
(4) The hybrid model is the most complex since it can comprise the other types of models, depending on the spatial distribution of local communities in the landscape. This model is probably the most realistic one for describing the spatial structure of populations and communities in real landscapes.

(5) Finally, the nonequilibrium model characterizes the existence of separated (highly fragmented) local communities of the same type, which may not persist in the long run in the absence of facilitated dispersal.

Naturally, the metacommunity types are not discrete entities, but lie instead along a continuum from nonequlibrium structure to the patchy structure. In addition, the hybrid model can contain all structures depending on the spatial scale, and therefore the other types can be a subset of the hybrid model. Note that this approach of typifying metacommunities is different from the method of Leibold and Mikkelson (2002) and Presley et al. (2010) for defining "elements of metacommunity structure". In the "elements of metacommunity structure" analyses the dominant species distributional pattern is characterized in rather arbitrarily selected sampling units which do not necessarily represent different local communities (for applications, see Meynard et al. 2013, Erős et al. 2014,2016a, Heino et al. 2015a,b,c). On the contrary, in the above approach (i.e., where metapopulation models are scaled up to the metacommunity level), the metacommunity types are delineated based on the distribution of different local communities in the landscape and the overall importance of dispersal of the dominant species to local community dynamics. Consequently, while the first approach explores the dominant community level pattern (e.g., nested, checkerboard, Clementsian, or Gleasonian), the latter approach looks for the relationships among spatially separated, but structurally (compositionally) similar local communities in a spatially explicit manner. I acknowledge that the latter approach is still conceptual at present, but its application to a real situation is beyond the scope of this special review. Such theoretical metacommunity models (Fig. 5) may provide the template for future empirical research, similarly to former metapopulation models (Schlosser and Angermeier 1995), which, although generated intense scientific debate (see e.g., Rieman and Dunham 2000, Schtickzelle and Quinn 2007, Falke and Fausch 2010), contributed largely to understanding the spatial distribution of fish populations in stream networks (Fullerton et al. 2011, Fullerton et al. 2016). In fact, the different approaches may effectively complement each other for understanding the organization of metacommunities in spatially heterogeneous stream habitats.

The dendritic network structure coupled with the dispersal abilities of species may determine the formation of different metacommunity types in stream systems (Fig. 5). For example, the formation of nonequilibrium metacommunities can be more expected in more isolated, high altitude, upstream areas than in downstream, more central areas. Headwater streams are typically occupied by species with low dispersal ability, which are relatively sedentary and move only small distances $\left(10^{0} \mathrm{~km}\right)$, usually not more than 1-3 km. Small bodied minnows (Cyprinidae) of the genus Phoxinus, as well as sculpins (Cottidae) and darters (Percidae) in streams of the temperate region are typically such species. Largely isolated springs or spring fed headwaters also have a unique fish fauna with many endemic species, for example from the genera Gambusia (Poeciliidae), Cyprinella (Cyprinidae), and Etheostoma (Percidae) (Hubbs 1995). The movement of these species through the environmentally non-preferred (i.e., matrix) downstream segments to other headwater segments is not easily feasible (Erős and Campbell-Grant 2015), but some rate of movement may be necessary to maintain community dynamics at some localities. In fact, the main task of metacommunity ecology is to explore the role of dispersal to local scale community dynamics in the metacommunity network.

Patchy or continuous metacommunities may form in the most downstream (potamon) sections of rivers. This is because of both the dispersal features of the most characteristic community constituting species and the relatively homogenous habitat features along very long reaches. The potamon and the lowest part of the rhithron is the habitat of the classic potamodromous and anadromous species with medium or high dispersal features, respectively. These species move intensively in the stream network between spawning, feeding and wintering refugee habitats (see Schlosser 1991) for relatively large distance $\left(10^{0}-10^{2} \mathrm{~km}\right.$ for potamodromous and $10^{2}-10^{3} \mathrm{~km}$ for anadromous species). Populations of potamodromous fishes may be hard to delineate and it is likely that they form patchy or rather continuous metapopulations in downstream segments. In addition, the spatial extent of the potamon is much longer than the movement distance of most of its characteristic species, such as those from the genera Barbus and Abramis (Cyprinidae) in Europe. Yet, relatively homogeneous communities can be found for hundreds or even thousands of kilometres in the potamon (McGarvey 2011, Erös et al. 2016b).

Source/sink metacommunities may also form in stream networks. For example, several studies show that mainstem fish use the lowest parts of adventitious streams for habitat. These species may modify the structure of the tributary by mass effect mechanisms since the long term maintenance of their populations may require continuous dispersal from the mainstem river (Thornbrugh and Gido 2010, Czeglédi et al.2015). Some run-off fed headwater streams, Mediterranean and desert streams which often dry to isolated reaches for months or years may also be characterized by source/sink metacommunity dynamics depending on the time scale of their isolation.

Finally, a hybrid model (which combines the characteristics of other models) may have the greatest reality in spatially and temporally variable stream networks, where fishes with diverse dispersal strategies interact. A challenge of stream (fish) ecology is a more mechanistic understanding of how differences in both network structure and the dispersal ability of species influence the spatial structure of metacommunity types. 


\section{Spatial organization of fish metacommunities in stream networks}

\section{Patterns in diversity}

For understanding metacommunity organization, the exact quantification of within and among site community structure and diversity is a prerequisite. Difficulties in estimating community parameters, however, can change with network position. Sampling becomes more difficult with increasing stream size, and requires multiple collecting devices (Flotemersch et al. 2011, Loisl et al. 2014, Erős et al.2016b). Overall, much higher sampling effort is needed for the same level of sample representativeness in the downstream sections of rivers, than in upstream areas (Fig. 6a,b, Cao et al. 2001, Erös 2007, Flotemersch et al. 2011). This calls attention to the critical importance of scaling in understanding within community (alpha) and between community (beta) diversity (Angermeier and Winston 1998, Pegg and Taylor 2007, Erös and Schmera 2010). While patterns in alpha diversity along the longitudinal profile of rivers are relatively wellknown (Matthews 1998), our knowledge is still limited on the scale-dependent changes of alpha and beta diversity, and their mutual effect in determining the regional scale (gamma) diversity of fish communities in stream networks.

It is likely that alpha diversity differs more between segments of the rhithron depending on the degree of isolation of the segments in the network. On the contrary, alpha diversity are supposed to be spatially and temporally more stable in the potamal section of large rivers, which are in more central position. This is both because between-segment environmental heterogeneity is greater in the rhithron and because dispersal limitation can increase stochastic (or chance) effects in more isolated upstream segments (Heino et al. 2015a). However, true differences in the number of species among different parts of the network can be realized only if sample unit size (or the number of smaller units) is large enough, since standardized (i.e., catch per unit effort) data can indicate different patterns among the segments depending on sampling effort (Fig. 6a,b). It is important to make distinction between the absolute (true) and the standardized number of species here. If alpha diversity is not explored enough (i.e., at small sample unit or small sample sizes, when species richness curves are far from saturation), differences among sampling units may be falsely related to beta diversity. Thus, stream ecologists should more intensively recognize that data interpretation and conclusions are dependent on how well samples characterize the investigated communities, including patterns in alpha and beta diversity (Cao et al. 2001, 2002, Schmera and Erös 2008, 2011).

It is also likely that true beta diversity (which is measured if alpha is correctly explored with saturation curves) may be higher in upstream (rhithral) than in downstream (potamal) segments. For example, in a recent study Vitorinó Junior et al. (2016) found that more isolated stream reaches showed higher species turnover than mainstem reaches in the Upper Tocantis River, Amazon basin. Similarly to patterns in alpha diversity, this is because upstream segments are generally more isolated

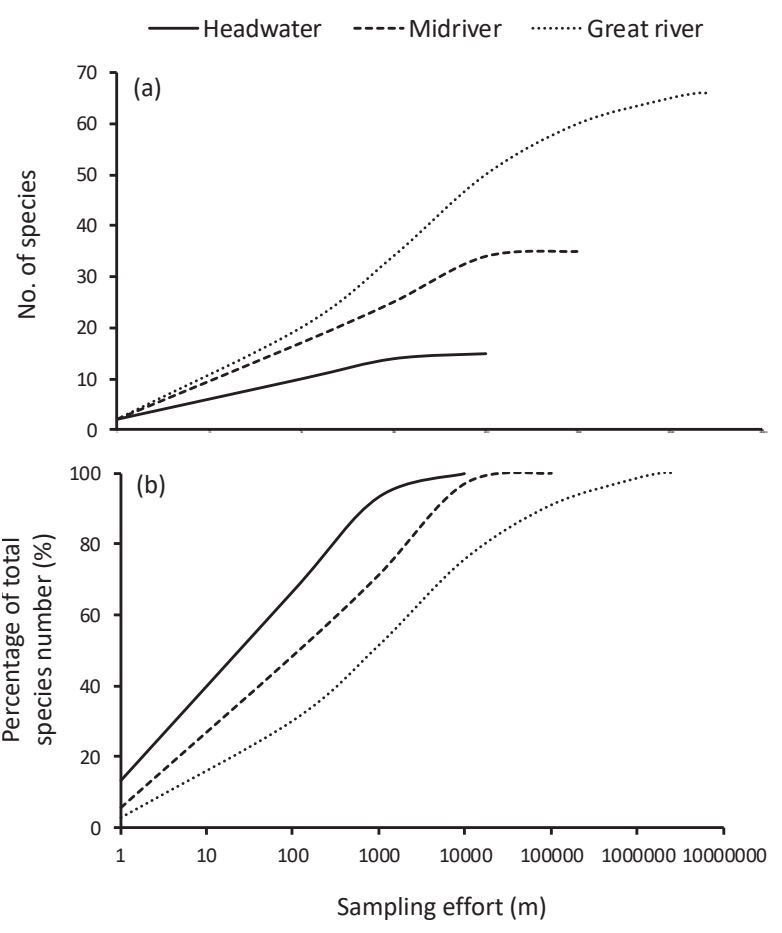

Figure 6. Changes in alpha diversity (species richness) as a function of sampling effort in a $10 \mathrm{~km}$ long headwater (1-3 Strahler order), in a $100 \mathrm{~km}$ long mid-river (4-6 Strahler order) and in a $>1000 \mathrm{~km}$ long great river ( $>6$ Strahler order) based on empirical evidence from the system of a great temperate river (the Danube River, Europe). Note that the $\mathrm{x}$-axis is measured on a logarithmic scale. Differences in alpha diversity among the stream types are expected to increase with increasing sampling effort (a), and the same level of sample representativeness (e.g., 80\%) requires approximately an order of magnitude higher sampling effort among headwater, midriver and great rivers (b).

from each other (Fig. 1), and therefore, both eco-evolutionary processes (i.e., response to differences in environmental heterogeneity) and dispersal limitation can generate higher beta diversity among sites in more upstream segments (Heino et al. 2015a). However, it must be emphasized that the value of beta diversity may depend largely on the examined spatial scale in case of upstream segments, since upstream segments can be either very close to or very far from each other in the network. Since the spatial distance of upstream segments embraces a much longer spatial gradient than for more central segments, it is expected that their beta diversity values can also range widely. Therefore, both spatial position and spatial distance between segments may strongly determine values of beta diversity in stream networks.

Position and distance effects may also interact with network structure or shape of the basin (e.g., heart vs elongated) to influence patterns in diversity. For example, there are indications that alpha diversity differs among tributary streams which are in different spatial position on the mainstem river, and that very simple indices of network structure can have further predictive power in determining alpha diversity (Osborne and Wiley 1992, Grenouillet et al. 2004). Hitt and Angermeier (2008) showed that the topology of stream 
networks influences fish dispersal dynamics, and that these effects are mediated by local stream size and the distance to connected streams. They emphasized that predictions of the $\mathrm{RCC}$ for fish community changes along the longitudinal profile of streams and rivers might be improved by using very simple measures, such as the size and proximity of connected streams. In an elongated river basin, Czeglédi et al. (2016) showed that spatial position of parallel tributaries along the river influenced community structure in the tributaries. Another example of dispersal effects comes from Perkin and Gido (2012) who proved that fragmentation of stream segments by road crossing caused significant changes in fish community structure. Isolated (i.e., fragmented) stream segments had reduced alpha diversity and increased beta diversity (greater dissimilarity) compared to communities that maintained connectivity with relatively natural (unfragmented) segments of the stream network.

Geomorphically significant confluences (Benda et al. 2004a,b, Rice 2017) alter hydromorphological conditions in the mainstem river, which may significantly influence habitat use, reproductive success, and in general, the fitness of constituting species. For example, different mesohabitat types (e.g., large islands) are formed above and below the confluence zone in the mainstem, which maintain different fish communities from the naturally flowing reaches to some extent (Ridenour et al. 2009, 2011). Since the number, distribution and significance of different mesohabitat patches differ among the different basin types (e.g., heart vs elongated), differences in their effect on the assembly of fish communities among the different basin types are expected. Further studies should indicate, however, whether and how these populationand species-level patterns and processes scale up to the metacommunity level.

Overall, the above predictions give a number of examples which should be further tested by stream ecologists to more clearly understand regional scale (meta)community structure, but are out of the scope of the predictions of the RCC. Despite promising results, the more intensive incorporation of network variables in predicting community structure is also warranted. Fortunately, the tools for quantifying the structure of stream networks are now available for stream ecologists (see above The habitat template: scaling the structure of stream networks section). Unfortunately, however, the number of relatively intact systems where pure network effects could be tested is very low. Testing network effects would require a number of intact systems from similar stream network types through the study of a number of replicate, rather than single, metacommunities (Tonkin et al. 2016).

\section{The importance of niche and dispersal processes in metacommunity organization}

An important research avenue of metacommunity ecology is the quantification of the role of environmental (niche) vs spatial (dispersal related) factors in landscape (regional) level community organization using variance partitioning in constrained ordination (Logue et al. 2011, Heino et al. 2015a). For stream fishes, several studies examined the roles of with- in stream (e.g., depth, substrate composition), landscape level (i.e., land use) and spatial factors on community structure. They generally found the paramount importance of environmental factors (niche based species sorting) over spatial constraints, although the explained variance fractions varied widely (see e.g., Peres-Neto and Cumming 2010, Sály et al. 2011, Kautza and Sullivan 2012, Hughes et al. 2015). Heino et al (2015) pointed out that the relative importance of the community structuring mechanisms can depend on the studied spatial scale. For example, the importance of dispersal limitation (which can be partly indicated by spatial factors in variance partitioning) increases with spatial distance among sites and spatial extent surveyed. Recent studies on stream fishes showed that the relative role of environmental and spatial factors is very context dependent and depends largely on stream network topology (Troia and Gido 2013, Sály and Erős 2016). For example, Sály and Erős (2015) proved that 1) the importance of variance fractions (environmental, spatial, and shared environmental and spatial) depended largely on sample size, and that 2) values of the estimated variance fractions had remarkable random fluctuation at a given sample size depending on the spatial configuration of the sites in the stream network.

Despite its context dependence, some fundamental conclusions can be drawn about the role of niche vs dispersal processes in stream networks, even if it is hard to test their relative importance with empirical data. For example, metacommunity theory predicts the increased importance of species sorting (i.e., environmental filtering) mechanisms in more isolated segments and a decrease in dispersal limitation in more central segments of the stream network (Brown and Swan 2010, Heino et al. 2012, Borthagaray et al. 2015a). This is because, during species sorting, biotic interactions and abiotic environmental conditions filter the suite of traits (species) which can co-occur in a given locality, provided there is enough dispersal so that species can track variation in environmental conditions (Leibold et al. 2004, Heino et al. 2015). However, again, dispersal may be not strong enough in isolated segments to mismatch patterns in environmental or biotic (e.g., competitive exclusion) relationships. On the contrary, high rates of dispersal may homogenize community structure in more central segments, allowing species to co-occur even under suboptimal conditions (mass effect mechanism). Here, dispersal may also preclude competitive exclusion or promote fast recolonization after extinction.

Interestingly, even the neutral model (i.e., which presumes that species traits have no role in affecting metacommunity dynamics) can make important predictions for the metacommunity organization of stream fish, which fits to field data. For example, the neutral theory predicts a reduction in species richness with increasing isolation. It also predicts that across a gradient of isolation, species poor communities tend to be subsamples of species rich ones, which yields a nested structure (Borthagaray et al. 2015a). Such patterns are typical in stream networks, where isolated headwater habitats are more species poor and form subsets of more downstream communities (Taylor and Warren 2001, Erős and Grossman 2005). 
Muneepaerakul et al. (2008) provided further convincing evidence for the applicability of neutral models in predicting large scale biodiversity patterns in stream fish communities by showing that beta diversity changed highly predictably as a function of topological distance and differences in water discharge ("habitat area") between subbasins. Nevertheless, patterns in richness, nestedness and species turnover are strongly related also to species sorting mechanisms, since the composition of fish communities in different stream habitat types is not random (Jackson et al. 2001, Erös 2007, Giam and Olden 2016), and environmental filtering is strongly related to species traits (Lamouroux et al. 2002, Olden et al. 2006, Olden and Kennard 2010). In fact, a major task of stream community ecologists is to define the role of niche based ecology over strictly neutral models to improve the predictability of patterns and processes in stream networks.

\section{Temporal dynamics of fish metacommunities in stream networks}

Former models of community organization predicted differences in the temporal variability of fish communities along the longitudinal gradient of streams (the stream continuum model), and expected high variability in upstream areas and relatively stable fish communities in downstream areas (Schlosser 1987, 1991). Recent alternative models may challenge this view. For example, Roberts and Hitt (2010) found temporally more variable fish communities in downstream than in upstream reaches in four of their five examined streams, which run counter with the stream continuum model. Miyazono and Taylor (2013) confirmed these findings, since they found more variable communities in downstream reaches due to the ingress and egress of riverine species at the mouths of tributaries and relatively stable communities in upstream isolated reaches, where community dynamics were determined by local species. This pattern fits the adventitious stream model which predicts greater temporal species turnover in downstream than upstream reaches (Roberts and Hitt 2010). This model emphasizes the importance of dispersal processes in community dynamics, which can overrule the role of local scale environmental variability. Further, although higher variability downstream maybe more contrasting in adventitious streams, this pattern is not exclusive to these type of streams (Erős and Schmera 2010). In sum, while several studies showed the significance of environmental variability and/or dispersal processes on community dynamics (e.g., Grossman et al. 1998, Oberdorff et al. 2001, Hitt and Roberts 2012, Grossman et al. 2010) the debate about the temporal variability of stream fish communities and its dependence on spatial network position is far from settled.

Recent challenges include determining temporal dynamics at the metacommunity level (i.e., in the network of communities linked by dispersal). Indeed, how could one reliably quantify temporal variability within and between fish metacommunities, if even the separation of local communities can cause difficulties in continuous habitats, such as streams? Determining the relative importance of processes that drive local (birth and death) and regional (immigration and emigra- tion) population dynamics in a set of species would be essential to clearly understand metacommunity dynamics. Testing the effect of network structure on metacommunity dynamics would also require long term sampling from a set of streams and rivers in relatively intact catchments. It is important to note that most studies which addressed the temporal variability of stream fishes in a network of stream sites examined small or medium sized streams (equal or less than 5 order in size; see e.g. Taylor and Warren 2001, Erös et al. 2012b). It would be important to quantify temporal variability in very large and great rivers, too, although, as stated above, quantifying temporal dynamics of fish communities in very large or great rivers is a great challenge due to the enormous size of the habitat (with, depth, lateral connections between the main channel and floodplain). In fact, representative sampling for even the species composition of middle size watersheds is a very difficult task both technically and logistically (Smith and Jones 2005).

One way to proceed forward is the more intensive combination of field work with modelling. Systematic, spatially and temporally intense sampling from a combination of stream segments would be essential to understand the effect of networks topology to (meta)population, and consequently, to metacommunity dynamics. For example, a series of elegant (field based) studies showed how the dynamics of stream salamander populations are influenced by very simple differences in the configuration of stream segments (Lowe 2002, Lowe and Bolger 2002, Campbell-Grant et al. 2009). Excellent modelling case studies also show the importance of network topology to the demography of stream fish (Fagan 2002, Labonne et al. 2008) and simulation experiments have been extended to "metacommunities" as well (Muneeperakul et al. 2007 a,b, Auerbach and Poff 2011). Indeed, a recent, promising approach uses graph-based network analysis to distinguish metacommunity networks and to determine scales at which investigating metacommunity dynamics is the most fruitful in the studied system using dispersal data of individual species (for details, see Borthagaray et al. $2015 \mathrm{a}, \mathrm{b}$ ). This approach could be adopted to stream networks as well. However, more long-term data on the population dynamics and movement patterns of stream fish in more complex networks (for an approach see Fullerton et al. 2016) would be essential to parameterize models for metacommunity dynamics (Jacobsen and Peres-Neto 2010, Erős and Campbell-Grant 2015). A combination of spatial occupancy data with more detailed information on dispersal and demography of community constituting species (for an excellent study, see Falke et al. 2015) could help to distinguish between metacommunity types in different landscapes (see Fig.5) and to determine critical scales of metacommunity dynamics.

\section{Implications for environmental management}

Currently, metacommunity models are more heuristic than predictive (Falke and Fausch 2010, Heino 2013). The most important task that metacommunity ecology can give to environmental management is to reveal the role of dispersal in the network of communities against local (i.e., within 
community) mechanisms. Several questions can be addressed in applied metacommunity research which could be a benefit to management in human altered landscapes. For example, what are the scales of metacommunities in the stream network where different local communities have the chance to interact? How can dispersal be maintained among local communities within a metacommunity? What are the most important local communities in the landscape, the conservation of which is critical for the maintenance of other communities in the metacommunity network?

Presently, most stream restoration efforts are arranged rather haphazardly by local authorities (national parks, water authorities, NGOs; Bernhardt et al. 2005). These restoration activities often fail, because they do not consider the importance of dispersal relationships in the landscape and/or because they wrongly address the protection of communities which are by far suboptimal for conservation (Bond and Lake 2003, Palmer et al. 2010, Tonkin et al. 2014, Schmutz et al. 2016). The key message of applied metacommunity research is a spatially more explicit, landscape scale consideration of between community relationships for the success of restoration and conservation. For example, large and more connected communities are probably more valuable than fragmented and/or small communities. In some cases, however, small and separate localities might have some of the most important rare species, such as isolated populations of darters that occupy only headwater reaches. In the case of a source/sink metacommunity, where mass effect mechanisms predominate, the most optimal strategy is to protect or restore the source community, which contributes the most to population dynamics in other habitats. In a naturally nonequilibrium metacommunity, the most suitable strategy is the protection of the most viable community(ies) (e.g., based on size, naturalness) and keeping local communities separated for keeping natural ecoevolutionary mechanisms. On the contrary, a highly altered and fragmented metacommunity may require the restoration of dispersal routes. Similarly, for a patchy metacommunity the long term maintenance of dispersal processes is essential.

Another important question in this regard is to answer how the spatial structure of metacommunities changes depending on network structure, because it is likely that network structure may significantly influence the value of local communities in a metacommunity for conservation purposes. Although large-scale conservation area selection methods (i.e., systematic conservation planning algorithms) are suitable to define biodiversity hotspots (e.g., Hermoso et al. 2011, Dolezsai et al. 2015), knowledge of the spatial structure of metacommunities is therefore useful to refine conservational programs and choose among the most valuable (meta)communities among and within these hotspots. Ideally, large-scale (i.e., national, continental), landscape scale (metacommunity) and local scale (community) conservation and restoration efforts should be designed in an integrative manner to select the network of local communities which are the most valuable for conservation actions. Forecasting changes in metacommunity dynamics due to climate change and a variety of human perturbation effects (e.g., deterioration of the habitat, fragmentation by dams) is an important applied research need, too.

\section{Conclusions}

In sum, several questions can be addressed based on this synthesis (Table 1), the answer of which may further our understanding on the dynamics and protection of metacommunities in stream networks. Here, I argued that while longitudinal patterns in the structure of fish communities are relatively well-known, our knowledge is still limited about how the structure of the stream network ultimately affects the spatial and temporal dynamics of metacommunities. I suggest that scaling metapopulation models up to the metacommunity level can be useful to characterize the spatial structure of metacommunities. This however, requires the delineation of local communities and the quantification of the contribution of dispersal to local community dynamics. Undoubtedly, this is a challenging task in continuous stream habitats, where some parts of the habitat network are exceptionally hard to sample representatively. Since most metacommunity level processes are likely to happen at the stream network level, further research on the effect of stream network structure is needed. Overall, separation of the effect of dispersal processes from local scale community dynamics may yield a more mechanistic understanding of the assembly of fish communities in stream networks, which may also enhance the effectiveness of restoration efforts.

Acknowledgments: This study was supported by the OTKA K-104279 and the GINOP 2.3.3-15-2016-00019 research funds. I am indebted to professors G. D. Grossman, W. J. Matthews and my colleagues for their comments on the ms and their suggestions for improvements.

\section{References}

Aarts, B.G.W., and P.H. Nienhuis. 2003. Fish zonations and guilds as the basis for assessment of ecological integrity of large rivers. Hydrobiologia 500: 157-178.

Altermatt, F., 2013. Diversity in riverine metacommunities: a network perspective. Aquat. Ecol. 47: 365-377.

Angermeier, P.L. and M.R. Winston. 1998. Local vs regional influences on local diversity in stream fish communities of Virginia. Ecology 79: 911-927.

Auerbach, D. and N. Poff. 2011. Spatiotemporal controls of simulated metacommunity dynamics in dendritic networks. J. North Am. Benthol. Soc. 30: 235-251.

Benda, L., N.L. Poff, D. Miller, T.Dunne, G. Reeves, G. Pess and M. Pollock. 2004a. The network dynamics hypothesis: How channel networks structure riverine habitats. Bioscience 54: 413-427.

Benda, L., K. Andras, D. Miller and P. Bigelow. 2004b. Confluence effects in rivers: Interactions of basin scale, network geometry, and disturbance regimes. Water Resour. Res. 40: W05402. ??

Bernhardt, E.S., M.A. Palmer, J.D. Allan, G. Alexander, K. Barnas, S. J. Brooks et al. 2005. Synthesizing US river restoration efforts. Science 308: 636-637.

Bond, N. R. and P. S. Lake. 2003. Local habitat restoration in streams: constraints on the effectiveness of restoration for stream biota. Ecol. Manag. Restor. 4: 193-198.

Borthagaray, A.I., M. Berazategui and M. Arim. 2015b. Disentangling the effects of local and regional processes on biodiversity pat- 
terns through taxon-contingent metacommunity network analysis. Oikos 124: 1383-1390.

Borthagaray, A.I., V. Pinelli, M. Berazategui, L. Rodrigúez-Tricot and M. Arim. 2015a. Effects of metacommunity networks on local community structures: from theoretical predictions to empirical evaluations. In A. Belgrano, G. Woodward and U. Jacob (eds.), Aquatic Functional Biodiversity An Ecological and Evolutionary Perspective. Elsevier, Amsterdam. pp. 75-114.

Brown, B.L. and C.M. Swan. 2010. Dendritic network structure constrains metacommunity properties in riverine ecosystems. $J$. Anim. Ecol. 79: 571-580.

Brown, B.L., C.M. Swan, D.A. Auerbach, E.H.C. Grant, N.P. Hitt, K.O. Maloney and C. Patrick. 2011. Metacommunity theory as a multispecies, multiscale framework for studying the influence of river network structure on riverine communities and ecosystems. J. North Am. Benthol. Soc. 30: 310-327.

Campbell-Grant E.H., W.H. Lowe and W.F. Fagan. 2007. Living in the branches: population dynamics and ecological processes in dendritic networks. Ecol. Lett. 10: 165-175.

Campbell-Grant E.H., L. Green and W.H. Lowe. 2009. Salamander occupancy in headwater stream networks. Freshwater Biol. 54: 1370-1378.

Cao, Y., D.P. Larsen and R.M. Hughes. 2001 Evaluating sampling sufficiency in fish assemblage surveys: a similarity-based approach. Can. J. Fish. Aquat. Sci. 58: 1782-1793.

Cao, Y., D.P. Larsen, R.M. Hughes, P.L. Angermeier and T.M. Patton. 2002. Sampling effort affects multivariate comparisons of stream assemblages. J. North Am. Benthol. Soc. 21: 704-714.

Chase, J.M. and J. Bengtsson. 2009. Increasing spatio-temporal scales: metacommunity ecology. In: M.A. Verhoef and P.J. Morin (eds.), Community Ecology, Processes, Models, and Applications, Oxford University Press, Oxford. pp. 57-68.

Clarke, A., R. MacNally, N. Bond and P.S. Lake. 2008. Macroinvertebrate diversity in headwater streams - a review. Freshwater Biol. 53: 1707-1721.

Czeglédi, I., P. Sály, P. Takács, A. Dolezsai, S.A. Nagy and T. Erős. 2016. The scales of variability of stream fish assemblages at tributary confluences. Aquat. Sci. 78: 641-654.

Didham, R.K., V. Kapos and R.M. Ewers. 2012. Rethinking the conceptual foundations of habitat fragmentation research. Oikos 121: $161-170$

Dolezsai, A., P. Sály, P. Takács, V. Hermoso and T. Erős. 2015. Restricted by borders: trade-offs in transboundary conservation planning for large river systems. Biodivers. Conserv. 24: 1403-1421.

Dray, S., R. Pélissier, P. Couteron, M.-J. Fortin, P. Legendre, P. R. Peres-Neto, E. Bellier, R. Bivand, F.G. Blanchet, M. De Cáceres, A.-B. Dufour, E. Heegaard, T. Jombart, F. Munoz, J. Oksanen, J. Thioulouse and H.H. Wagner. 2012. Community ecology in the age of multivariate multiscale spatial analysis. Ecol. Mon. 82: $257-275$

Erős, T. 2007. Partitioning the diversity of riverine fish: the roles of habitat types and non-native species. Freshwater Biol. 52: 1400-1415.

Erős, T. and G.D. Grossman. 2005. Effects of within patch habitat structure and variation on fish assemblage characteristics in the Bernecei stream, Hungary. Ecol. Freshwat. Fish. 14: 256-266.

Erős, T. and D. Schmera. 2010. Spatio-temporal scaling of biodiversity and the species-time relationship in a stream fish assemblage. Freshwater Biol. 55: 2391-2400.
Erös, T., D. Schmera and R.S. Schick. 2011. Network thinking in riverscape conservation - a graph-based approach. Biol. Cons. 144: $184-192$

Erős, T., J.D. Olden, R.S. Schick, D. Schmera and M. Fortin. 2012a. Characterizing connectivity relationships in freshwaters using patch-based graphs. Landscape Ecol. 27: 303-317.

Erős, T., P. Sály, P. Takács, A. Specziár and P. Bíró. 2012b. Temporal variability in the spatial and environmental determinants of functional metacommunity organization - stream fish in a humanmodified landscape. Freshwater Biol. 57: 1914-1928.

Erős, T., P. Sály, P. Takács, C.M. Higgins, D. Schmera and P. Bíró 2014. Quantifying temporal variability in the metacommunity structure of stream fishes: the influence of non-native species and environmental drivers. Hydrobiologia 722: 31-43.

Erős, T. and E.H. Campbell-Grant. 2015. Unifying research on the fragmentation of terrestrial and aquatic habitats: patches, connectivity and the matrix in riverscapes. Freshwater Biol. 60: $1487-1501$.

Erős, T., P. Takács, A. Specziár, D. Schmera and P. Sály. 2017. Effect of landscape context on fish metacommunity structuring in stream networks. Freshwater Biol. 62: 215-218.

Erős, T., V. Bammer, Á.I. György, L. Pehlivanov, M. Schabuss, H. Zornig, A. Weiperth and Z. Szalóky. 2016b. Typology of a great river using fish assemblages: Implications for the bioassessment of the Danube River. River Res. Appl. 33: 37-49.

Fagan, W.F., 2002. Connectivity, fragmentation, and extinction risk in dendritic metapopulations. Ecology 83: 3243-3249.

Falke, J.A., L.L.Bailey, K.D. Fausch and K.R. Bestgen. 2012. Colonization and extinction dynamics in dynamic habitats: an occupancy approach for a Great Plains stream fish assemblage. Ecology 93: 858-867.

Falke, J.A. and K.D. Fausch. 2010. From metapopulations to metacommunities: linking theory with empirical observations of the spatial population dynamics in stream fishes. In: K.B. Gido and D.A. Jackson (eds.), Community Ecology of Stream Fishes: Concepts, Approaches, and Techniques. American Fisheries Society, Symposium 73, Bethesda, Maryland. pp. 207-233.

Fausch, K.D., C.E. Torgersen, C.V. Baxter and H.W. Li. 2002 Landscapes to riverscapes: Bridging the gap between research and conservation of stream fishes. Bioscience 52: 483-498.

Fausch, K.D. 2010. Preface: A Renaissance of stream fish ecology. In: K.B. Gido and D.A. Jackson (eds.), Community Ecology of Stream Fishes: Concepts, Approaches, and Techniques. American Fisheries Society, Symposium 73, Bethesda, Maryland. pp. 199-206.

Finn, D., N. Bonada, C. Múrria and J. Hughes. 2011. Small but mighty: Headwaters are vital to stream network biodiversity at two levels of organization. J. North Am. Benthol. Soc. 30: 963-980.

Fisher, S. 1997. Creativity, idea generation, and the functional morphology of streams. J. North Am. Benthol. Soc. 16: 305-318.

Flotemersch, J.E., J.B. Stribling, R.M. Hughes, L. Reynolds, M.J. Paul and C. Wolter. 2011. Site length for biological assessment of boatable rivers. River Res. Appl. 27: 527-535.

Fullerton, A.H., S.T. Lindley, G.R. Pess, B.E. Feist, E.A. Steel and P. McElhany. 2011. Human influence on the spatial structure of threathened pacific salmon metapopulations. Conserv. Biol. 25: 932-944

Fullerton, A.H., S. Anzalone, P. Moran, D.M. van Doornik, T Copeland and R.W. Zabel. 2016. Setting spatial conservation priorities despite incomplete data for characterizing metapopulations. Ecol. Appl. 26: 2560-2580. 
Ganio, L.M., C.E. Torgersen and R.E. Gresswell. 2005. A geostatistical approach for describing spatial pattern in stream networks. Fron. Ecol. Env. 3: 138-144.

Giam, X. and J.D. Olden. 2016. Environment and predation govern fish community assembly in temperate streams. Global Ecol. Biogeogr. 25: 1194-1205.

Gorman, O. 1986. Assemblage organization of stream fishes: the effect of rivers on adventitious streams. Amer. Nat. 128: 611-616.

Göthe, E., D.G. Angeler and L. Sandin. 2013. Metacommunity structure in a small boreal stream network. J. Anim. Ecol. 82: 449-458.

Grave,1 D., C.D. Canham, M. Beaudet and C. Messier. 2006. Reconciling niche and neutrality: the continuum hypothesis. Ecol. Lett. 9: 399-409.

Grenouillet, G., D. Pont and K.L. Seip. 2004. Within-basin fish assemblage structure: the relative influence of habitat versus stream spatial position on local species richness. Can. J. Fish. Aquat. Sci. 61: 93-102.

Grossman, G.D., R.E. Ratajczak, M.D. Jr. Farr, M. C. Wagner and J.D. Petty. 2010. Why there are fewer fish upstream? In: K.B. Gido and D.A. Jackson (eds.), Community Ecology of Stream Fishes: Concepts, Approaches, and Techniques. American Fisheries Society, Symposium 73, Bethesda, Maryland. pp. 63-82.

Grossman, G.D., R.E. Ratajzak, M. Crawford and M.C. Freeman. 1998. Assemblage organisation in stream fishes: effects of environmental variation and interspecific interactions. Ecol. Mon. 68: $395-420$

Grossman, G.D., J.F. Dowd and M. Crawford. 1990. Assemblage stability in stream fishes: a review. Environ. Manage. 14: 661-671.

Harrison, S. and A.D. Taylor. 1997. Empirical evidence for metapopulation dynamics. In: I.A. Hanski and M.E. Gilpin (eds.), Metapopulation Biology: Ecology, Genetics, and Evolution. Academic Press, San Diego, California. pp. 27-42.

Harrison, S. 1991. Local extinction in a metapopulation context: an empirical evaluation. Biol. J. Linn. Soc. 42: 73-88.

Heino, J. 2013. The importance of metacommunity ecology for environmental assessment research in the freshwater realm. Biol. Rev. 88: 166-178

Heino, J., A. Melo, T. Siqueira, J. Soininen, S. Valanko and L.M. Bini. 2015a. Metacommunity organization, spatial extent and dispersal in aquatic systems: patterns, processes and prospects. Freshwater Biol. 60: 845-869.

Heino, J., T. Nokela, J. Soininen, M. Tolkinnen, L. Virtanen and R. Virtanen. 2015b. Elements of metacommunity structure and community-environment relationships in stream organisms. Freshwater Biol. 60: 973-988.

Heino, J., J. Soininen, J. Alahuhta, J. Lappalainen and N. Virtanen. 2015c A comparative analysis of metacommunity types in the freshwater realm. Ecol. Evol. 5: 1525-1537.

Hermoso, V., S. Linke, J. Prenda and H.P. Possingham. 2011. Addressing longitudinal connectivity in the sytematic conservation planning for freshwaters. Freshwater Biol. 56: 57-70.

Hitt, N.P. and P.L. Angermeier. 2008. Evidence for fish dispersal from spatial analysis of network topology. J. North Am. Benthol. Soc. 27: 304-320.

Hitt, N.P. and J. H. Roberts. 2012. Hierarchical spatial structure of stream fish colonization and extinction. Oikos 121: 127-137.

Hubbs, C. 1995, Perspectives: Springs and spring runs as unique aquatic systems. Copeia 1995. 989-991.

Hughes, R.M., A.T. Herlihy and J.C. Sifneos. 2015. Predicting aquatic vertebrate assemblages from environmental variables at three multistate geographic extents of the western USA. Ecol. Indic. 57: 546-556.

Illies, J. and L. Botosaneanu. 1963, Problèmes et méthodes de la classification et de la zonation écologique des eaux courantes, considerées surtout du point de vue faunistique. Verh. Int. Ver. Theor. Angew. Limnol. 12: 1-57.

Jackson, D.A., P.R. Peres-Neto and J.D. Olden. 2001. What controls who is where in freshwater fish communities - the roles of biotic, abiotic and spatial factors. Can. J. Fish. Aquat. Sci. 58: 157-170.

Jackson, D.A. 2010. Cluster analysis of fish community data: "new" tools for determining meaningful groups of sites and species assemblages. In: K.B. Gido and D.A. Jackson (eds.), Community Ecology of Stream Fishes: Concepts, Approaches, and Techniques. American Fisheries Society, Symposium 73, Bethesda, Maryland. pp. 503-527.

Jacobson, B- and P.R. Peres-Neto. 2010. Quantifying and disentangling dispersal in metacommunities: how close have we come? How far is there to go? Lands. Ecol. 25: 495-507.

Kautza, A. and S.M.P. Sullivan. 2012. Relative effects of local- and landscape-scale environmental factors on stream fish assemblages: evidence from Idaho and Ohio, USA. Fund. Appl. Limnol. 180: 259-270.

Labonne, J., V. Ravigné, B. Parisi and C. Gaucherel. 2008. Linking dendritic network structures to population demogenetics: the downside of connectivity. Oikos 117: 1479-1490.

Lamouroux N., N.L. Poff and P.L. Angermeier. 2002. Intercontinental convergence of stream fish community traits along geomorphic and hydraulic gradients. Ecology 83: 1792-1807.

Lasne, E., B. Bergerot, S. Lek, and P. Laffaille. 2007. Fish zonation and indicator species for the evaluation of the ecological status of rivers: example of the Loire basin (France). River Res. Appl. 23: $877-890$.

Legendre, P. and L. Legendre. 1998. Numerical Ecology. Elsevier, Amsterdam, The Netherlands, pp. $\mathrm{xv}+853$.

Leibold, M.A., M. Holyoak, N. Mouquet, P. Amarasekare, J.M. Chase, M.F. Hoopes, R.D. Holt, J.B. Shurin, R. Law, D. Tilman, M. Loreau and A. Gonzalez. 2004. The metacommunity concept: a framework for multi-scale community ecology. Ecol. Lett. 7: 601-613.

Leibold, M.A. and G.M. Mikkelson. 2002. Coherence, species turnover and boundary clumping: elements of a metacommunity structure. Oikos 97: 237-250.

Logue, J.B., N. Mouquet, H. Peter, H. Hillebrand, P. Declerck, A. Flohre, S. Gantner, N. Gülzow, P. Hörtnagl, S. Meier and B. Pecceu. 2011. Empirical approaches to metacommunities: a review and comparison with theory. TREE 26: 482-491.

Loisl, F., G. Singer and H. Keckeis. 2014. Method-integrated fish assemblage structure at two spatial scales along a free-flowing stretch of the Austrian Danube. Hydrobiologia 729: 77-94.

Lowe, W.H. 2002 Landscape-scale spatial population dynamics in human-impacted stream systems. Environ. Manage. 30: 225233.

Lowe, W.H. and D.T. Bolger. 2002. Local and landscape scale predictors of salamander abundance in New Hampshire headwater streams. Conserv. Biol. 16: 183-193.

Lucas, M.C., E. Baras, T.J. Thom, A. Duncan and O. Slavík. 2001. Migration of Freshwater Fishes. Blackwell Science.

Matthews, W.J. 1986. Fish faunal breaks and stream order in the Eastern United States. Environ. Biol. Fish. 17: 81-92.

Matthews, W.J. 1998. Patterns in Freshwater Fish Ecology. Chapman and Hall, New York 
Matthews, W.J. and H.W. Robison. 1998. Influence of drainage connectivity, drainage area, and regional species richness on fishes of the interior highlands in Arkansas. Am. Midl. Nat. 139: 1-19.

Matthews, W.J. 2010. Community ecology of stream fishes: two decades later. In: K.B. Gido and D.A. Jackson (eds.), Community Ecology of Stream Fishes: Concepts, Approaches, and Techniques. American Fisheries Society, Symposium 73, Bethesda, Maryland. pp. 3-19.

McGarvey, D.J. 2011. Quantifying ichthyofaunal zonation and species richness along a $2800-\mathrm{km}$ reach of the Rio Chama and Rio Grande (USA). Ecol. Freshwat. Fish 20: 231-242.

Meynard, C.N., S. Lavergne, I. Boulangeat, L. Garraud, J. Van Es, N. Mouquet and W. Thuiller. 2013. Disentangling the drivers of metacommunity structure across spatial scales. J. Biogeogr. 40 $1560-1571$.

Miyazono, S. and C.M. Taylor 2013. Effects of habitat size and isolation on species immigration-extinction dynamics and community nestedness in a desert river system. Freshwater Biol. 58: 1303-1312.

Muneepeerakul, R., E. Bertuzzo, H.J. Lynch, W.F. Fagan, A. Rinaldo and I. Rodriguez-Iturbe. 2008. Neutral metacommunity patterns predict fish diversity patterns in Mississippi-Missouri basin. Nature 453: 220-222.

Muneepeerakul, R., S.A. Levin, 2007a. On biodiversity in river networks: a tradeoff metapopulation model and comparative analysis. Water Resour. Res. 43:W07426.

Muneepeerakul, R., S.A. Weitz, SA Levin, A. Rinaldo and I. Rodriguez-Iturbe. 2007b. A neutral metapopulation model of biodiversity in river networks. J. Theor. Biol. 245: 351-363.

Oberdorff, T., B. Hugueny, and T. Vigneron. 2001. Is assemblage variability related to environmental variability? An answer for riverine fish. Oikos, 93: 419-428.

Olden, J.D. and M. Kennard. 2010. Intercontinental comparison of fish life history strategies along a gradient of hydrologic variability. In: In: K.B. Gido and D.A. Jackson (eds.), Community Ecology of Stream Fishes: Concepts, Approaches, and Techniques. American Fisheries Society, Symposium 73, Bethesda, Maryland. pp. 83-108.

Olden, J.D., N.L. Poff and K.R. Bestgen. 2006. Life-history strategies predict fish invasions and extirpations in the Colorado River basin. Ecol. Mon. 76: 25-40.

Osborne, L.L. and M.J. Wiley. 1992. Influence of tributary spatial position on the structure of warmwater fish communities. Can. J. Fish. Aquat. Sci., 49: 671-681.

Palmer, M.A., H.L. Menninger and E. Bernhardt. 2010. River restoration, habitat heterogeneity and biodiversity: a failure of theory or practice? Freshwater Biol. 55: 205-222.

Pegg, M. A. and R. M. Taylor. 2007. Fish species diversity among spatial scales of altered temperate rivers. J. Biogeogr. 34: 549558.

Peres-Neto, P.R. and G.S. Cummins. 2010. A multi-scale framework for the analysis of fish metacommunities. In: K.B. Gido and D.A. Jackson (eds.), Community Ecology of Stream Fishes: Concepts, Approaches, and Techniques. American Fisheries Society, Symposium 73, Bethesda, Maryland. pp. 235-262.

Perkin, J. S. and K.B. Gido. 2012. Fragmentation alters stream fish community structure in dendritic ecological networks. Ecol. Appl. 22: 2176-2187.

Peterson, E.E., J.M. Ver Hoef, D.J. Isaak et al. 2013. Modelling dendritic ecological networks in space: an integrated network perspective. Ecol. Lett. 16: 707-719.
Poole, G.C. 2002. Fluvial landscape ecology: addressing uniqueness within the river discontinuum. Freshwater Biol. 47: 641-660.

Poole, G.C. 2006. Stream hydrogeomorphology as a physical science basis for advances in stream ecology. J. North Am. Benthol. Soc. 29: $12-25$

Presley, S.J., C.L. Higgins and M.R. Willig. 2010. A comprehensive framework for the evaluation of metacommunity structure. Oikos, 119: 908-917.

Rice, S.P. 2017. Tributary connectivity, confluence aggradation and network biodiversity. Geomorphology, 277: 6-16.

Rice, S.P., A.G. Roy and B.L. Rhoads. 2008. River Confluences, Tributaries and the Fluvial Network. Wiley, New York.

Ridenour, C.J., W.J. Doyle and T.D. Hill. 2011. Habitats of age-0 sturgeon in the Lower Missouri River. Trans. Am. Fish. Soc. 140: 1351-1358.

Ridenour, C.J., A.B. Starostka, W.J. Doyle and T.D. Hill. 2009 Habitat used by Macrohybsis chubs associated with channel modifying structures in a large regulated river: implications for river modifications. River Res. Appl. 25: 472-485.

Rieman, B.E. and J.B. Dunham. 2000. Metapopulations and salmonids: a synthesis of life history patterns and empirical observations. Ecol. Freshwat. Fish 9: 51-64.

Roberts, J.H. and N.P. Hitt 2010. Longitudinal structure of stream fish communities: evaluating conceptual models with temporal data. Amer. Fish. Soc. Symp. 73: 281-299.

Sály, P. and T. Erős. 2015. Effect of field sampling design on variance partitioning. Ecol. Compl. 28: 187-199.

Sály, P., P. Takács, I. Kiss, P. Bíró and T. Erős. 2011. The relative influence of spatial context and catchment- and site-scale environmental factors on stream fish assemblages in a human-modified landscape. Ecol. Freshwat. Fish 20: 251-252.

Schaeffer, J.F. and J.R. Kerfoot. 2004. Fish assemblage dynamics in an adventitious stream: a landscape perspective. Am. Midl. Nat. 151: $134-145$

Schlosser, I.J. 1982. Fish community structure and function along two habitat gradients in a headwater stream. Ecol. Mon. 52: 395-414.

Schlosser, I.J. 1985. Flow regime, juvenile abundance, and the assemblage structure of stream fishes. Ecology 66: 1484-1490.

Schlosser, I.J. 1987. A conceptual framework for fish communities in small warmwater streams. In: W.J. Matthews and D.C. Heins, (eds.), Community and Evolutionary Ecology of North American Stream Fishes. University of Oklahoma Press, Norman, OK. pp. $17-24$

Schlosser, I.J. 1991. Stream fish ecology: A landscape perspective. Bioscience 41: 704-712.

Schlosser, I.J. and P.L. Angermeier. 1995. Spatial variation in demographic processes in lotic fishes: Conceptual models, empirical evidence, and implications for conservation. Amer. Fish. Soc. Symp. 17: 360-370.

Schmera, D. and T. Erős. 2008 Linking scale and diversity partitioning in comparing species diversity of caddisflies in riffle and pool habitats. Arch. Hydrobiol. 172: 205-215.

Schmera, D. and T. Erős. 2011. The role of sampling effort, taxonomical resolution and abundance weight in multivariate comparison of stream dwelling caddisfly assemblages collected from riffle and pool habitats. Ecol. Ind. 11: 230-239.

Schmutz, S., P. Jurajda, S. Kaufmann, A. Lorenz, S. Muhar, A. Paillex, M. Poppe and C. Wolter. 2016. Response of fish assemblages to hydromorphological restoration in central and northern European rivers. Hydrobiologia 769: 67-78. 
Schtickzelle, N. and T.P. Quinn. 2007. A metapopulation perspective for salmon and other anadromous fish. Fish Fish. 8: 297-314.

Smith, K.L. and M.L. Jones. 2005. Watershed-level sampling effort requirements for determining riverine fish species composition. Can. J. Fish. Aquat. Sci. 62: 1580-1588.

Taylor, C.M. and M.L. Warren. 2001. Dynamics in species composition of stream fish assemblages: environmental variability and nested subsets. Ecology 82: 2320-2330.

Thornbrugh, D.J. and K.B. Gido. 2010. Influence of spatial positioning within stream networks on fish assemblage structure in the Kansas River basin, USA. Can. J. Fish. Aquat. Sci. 67: 143-156.

Thorp, J.H., M.C. Thoms and M.D. Delong. 2006. The riverine ecosystem synthesis: biocomplexity in river networks across space and time. River Res. Appl. 22: 123-147.

Thorp, J.H. 2014. Metamorphosis in river ecology: from reaches to macrosystems. Freshwater Biol. 59: 200-210.

Tonkin, J.D., J. Heino, A. Sundermann, P. Haase and S.C. Jähnig. 2016. Context dependency in biodiversity patterns of central German stream metacommunities. Freshwater Biol. 61: 607620 .

Tonkin, J.D., Stoll S., A. Sundermann and P. Haase. 2014. Dispersal distance and the pool of taxa, but not barriers, determine the colonisation of restored river reaches by benthic invertebrates. Freshwater Biol. 59: 1843-1855.

Troia, M.J. and K.B. Gido. 2013. Predicting community-environment relationships of stream fishes across multiple drainage basins: Insights into model generality and the effect of spatial extent. J. Environ. Manage. 15: 313-323.
Vannote, R.L., G.W. Minshall, K.W. Cummins, J.R. Sedell and C.E. Cushing. 1980. The river continuum concept. Can. J. Fish. Aquat. Sci. 37: 130-137.

Vellend, M. 2010. Conceptual synthesis in community ecology. Quart. Rev. Biol. 85: 183-206.

Vitorino, O.B. Júnior, R. Fernandes, C.S. Agostinhoand, F.M. Pelicice. 2016 Riverine networks constrain $\beta$-diversity patterns among fish assemblages in a large Neotropical river. Freshwater Biol. 61: 1733-1745.

Welcomme, R.L. 1985. River Fisheries. FAO Fisheries Technical Paper 262: $330 \mathrm{p}$.

Winegardner, A.K., B.K. Jones, I.S.Y. Ng, T. Siguera and K. Cottenie. 2012. The terminology of metacommunity ecology. TREE 27 : 253-254.

Zalewski, M., P. Frankiewicz, M. Przybylski, J. Banbura and M. Nowak. 1990. Structure and dynamics of fish communities in temperate rivers in relation to the abiotic-biotic regulatory concept. Pol. Arch. Hydrobiol. 37: 151-176.

Received April 17, 2017

Revised May 5, 2017

Accepted May 12, 2017

Open Access. This article is distributed under the terms of the Creative Commons Attribution 4.0 International License (https://creativecommons.org/licenses/by/4.0/), which permits unrestricted use, distribution, and reproduction in any medium, provided the original author and source are credited, you give a link to the Creative Commons License, and indicate if changes were made. 